\title{
IDENTIFICAÇÃO DE CUTANS EM PERFIS DE LATOSSOL ROXO E TERRA ROXA ESTRUTURADA *
}

\author{
S. C. FALCI ** \\ A. C. Teixeira Mendes
}

RESUMO

\begin{abstract}
O presente trabalho teve por finalidade o estudo de cutans em dois perfis de solos pertencentes ao grande grupo Latossol Roxo (série Iracema, Município de Piracicaba, SP), e em dois perfis do grande grupo Terra Roxa Estruturada (Município de Botucatu, SP).

Tal estudo baseou-se no exame das amostras dos perfis, em secções delgadas examinadas sob microscópio petrográfico.

A análise de uma boa quantidade de lâminas revelou a presença de cutans iluviais nos horizantes $B_{21}$ dos Lotossóis Roxos, no horizonte $B_{1}$ e parte do $B_{21}$ do perfil $P_{3}$ (Terra Roxa Estruturada) e nos horizontes $B_{21}$ e $B_{22}$ do perfil $P_{4}$ (Terra Roxa Estruturada).
\end{abstract}

\section{INTRODUÇAOO}

Após a introdução dos modernos conceitos (adição, perda, transformação e transporte) de SIMONSON (1959) para o estudo da gênese dos solos, aquelas ciências, como por exemplo a Mineralogia Óptica e Cristalografia, que se achavam mais ligadas à Sedimentologia e Petrologia, passaram a ter um papel relevante na Pedologia.

No entanto, atualmente os estudos de gênese de solos no Brasil e em particular no Estado de São Paulo, têm-se restringido essencialmente ao estabelecimento de uma sequência de evolução dos solos baseada em sua fração coloidal (MONIZ \& JACKSON, 1967; DEMATTÊ, 1968, 1970; CARVALHO, 1970; ANDRADE, 1971).

Por outro lado, importantíssimos aspectos genéticos de certos solos, como por exemplo o diagnóstico dos horizontes argílicos, espódicos, etc., não podem ser estudados tomando-se como base unicamente o processo de trans-

* Entregue para publicação em 25/7/1973; trabalho realizado com parte dos dados da dissertação apresentada à E.S.A. «Luiz de Queiroz» para obtenção do título de Mestre, pela Eng Agr Sonia Carmela Falci.

* Pós-Graduada da E. S. A. «Luiz de Queiroz» e bolsista da Fundação de Amparo à Pesquisa do Estado de São Paulo, à qual agradece pela Bolsa de Aperfeiçoamento.

*** Professor de Disciplina do Departamento de Solos e Geologia. E.S.A. \&Luiz de Queiroz», Universidade de São Paulo. 
formação. Há necessidade para tal fim, de se trabalhar com os processos de transferência de material coloidal. A Micropedologia neste caso, reveste-se de fundamental importância. No entanto, até o presente são poucos os pesquisadores brasileiros que estão se dedicando a esse ramo da Ciência do Solo. Entre outros trabalhos dignos de menção, estão os realizados por MOURA FILHO (1968, 1970), CARVALHO (1970) e LEMOS (BENNEMA et al., 1970).

Dentro do processo genético de transferência de material no interior do perfil, a identificação das cutans (cerosidade, «clay skins», etc.), é básica para o reconhecimento de certos horizontes como o argílico e nátrico. Em muitos casos, por falta de resultados micropedológicos, a classificação do solo e sua interpretação genética pode ser falha (DEMATTÊ, 1970).

BREWER (1964) definiu as cutans como modificações na textura, estrutura e «fabric» de superfícies naturais no material do solo devidas à concentração de componentes particulares, ou modificações in siłu do plasma, podendo ser compostas de quaisquer substâncias componentes do material do solo.

Tomando-se como base estes pontos de vista, é que se propôs a realização deste trabalho. Para tal estudo foram coletados quatro perfis de solos, situados dois no Município de Piracicaba e dois no de Botucatu. Os perfis situados no Município de Piracicaba foram classificados como Latossol Roxo, e aqueles no de Botucatu como Terra Roxa Estruturada.

Não é pretensão nenhuma neste trabalho, cobrir todo o vasto campo abrangido pela Micropedologia, e sim o de dar uma contribuição para a elucidação dos muitos problemas existentes em nossos solos.

Serão estudados aqui, apenas os aspectos microscópicos da cutan, e sua posterior interpretação para finalidades taxonômicas e genéticas.

\section{MATERIAIS E MÉTODOS}

$\mathrm{Na}$ elaboração do presente trabalho foram utilizados os materiais e métodos descritos a seguir:

\section{Materiais}

Foram incluídos como materiais os solos, o material usado na impregnação e os aparelhos e utensílios.

\section{Solos}

O trabalho proposto tem como objetivo o estudo microscópico das cutans em alguns perfis de solos que ocorrem no Estado de São Paulo. Selecionaramse assim, através do trabalho da COMISSÃO DE SOLOS DO CNEPA (1960), dois grandes grupos de solos: Latossol Roxo e Terra Roxa Estruturada. Da primeira unidade de mapeamento foram estudados dois perfis situados no Município de Piracicaba, e da segunda, dois perfis localizados no Município de Botucatu. 


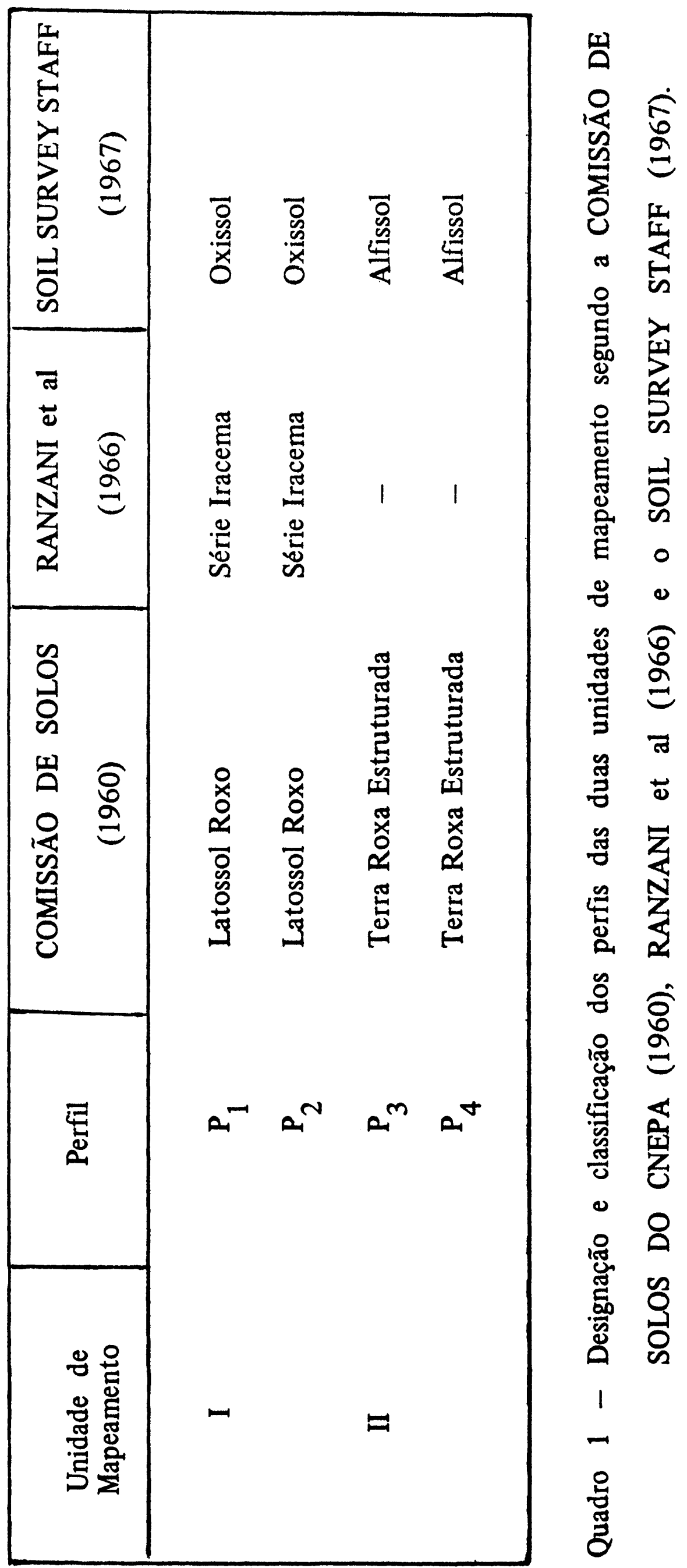


A classificação dos perfis estudados de acordo com diversos autores achase representada no quadro 1.

Os perfis $\mathrm{P}_{1}$ e $\mathrm{P}_{2}$ estão localizados a $2 \mathrm{~km}$ da margem direita da rodovia que liga a cidade de Piracicaba a Santa Bárbara D'Oeste, e a $12 \mathrm{~km}$ da primeira, sendo o perfil $P_{1}$ situado na parte alta da encosta, e o $P_{2}$ na parte média da mesma. Algumas características morfológicas de ambos acham-se apresentadas no quadro 2.

Os perfis $\mathrm{P}_{3}$ e $\mathrm{P}_{4}$ estão localizados a $7 \mathrm{~km}$ da cidade de Botucatu e a 200 $\mathrm{m}$ da margem esquerda da rodovia que a liga ao distrito de Vitoriana, sendo o perfil $\mathrm{P}_{3}$ localizado na meia encosta e o $\mathrm{P}_{4}$ distante $300 \mathrm{~m}$ do $\mathrm{P}_{3}$, na parte baixa da encosta. Algumas características morfológicas de ambos acham-se apresentadas no quadro 3 .

\section{Materiais usados na impregnação}

Resina Polylite T 213 produzida pela Resana S/A, Indústrias Químicas, São Paulo.

Monômero de estireno.

Peróxido de metil etil cetona (peróxido de MEK, produzido pela Resana S/A, Indústrias Químicas, São Paulo).

Frascos cilíndricos de vidro com aproximadamente $4 \mathrm{~cm}$ de diâmetro e $7 \mathrm{~cm}$ de altura.

\section{Aparelhos e utensílios}

Microscópio petrográfico. Utilizou-se um, de fabricação da Ernest Leitz Wetzlar, Alemanha, modelo Dialux-Poll. Uma câmara Minolta SRT, acoplada com adaptador Minolta para ocular de microscópio, foi utilizada na obtenção das microfotografias.

Equipamento para corte das amostras de solo impregnadas. Utilizou-se uma serra elétrica com disco de diamante produzida pela Felker Di-Met Manufacturing Company, Estados Unidos, modelo 11R.

Equipamento para desgaste das secções. Esta operação foi realizada em um prato de lapidação rotativo de fabricação da R. Fuess, Alemanha.

Equipamento para impregnação. Utilizou-se um montado no Laboratório de Mineralogia de Solos (Departamento de Solos e Geologia, Escola Superior de Agricultura «Luiz de Queiroz», USP) baseado em um apresentado por BREWER (1964), e conforme descrito por TEIXEIRA MENDES et al (1973).

Bomba de vácuo com motor de $1 / 4$ de HP.

Chapa aquecedora de lâmina. Utilizou-se uma, de fabricação da Eberbach Corporation, Michigan, Estados Unidos.

Estufa com regulagem de temperatura. Foi utilizada uma, modelo 1078 $1 / 2$, de fabricação da WM. Boekel and Company, Inc., Philadelphia, Estados Unidos. 


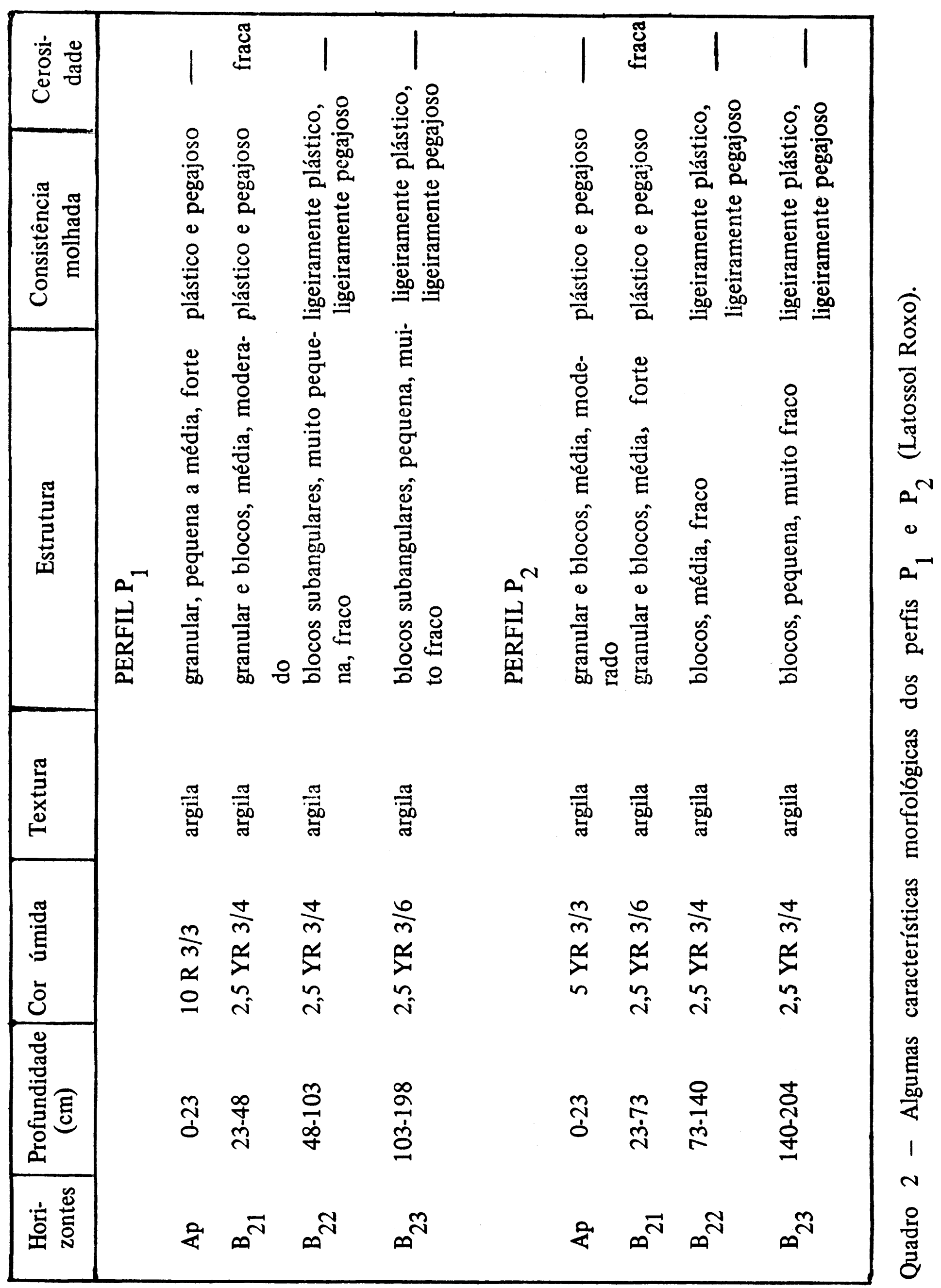




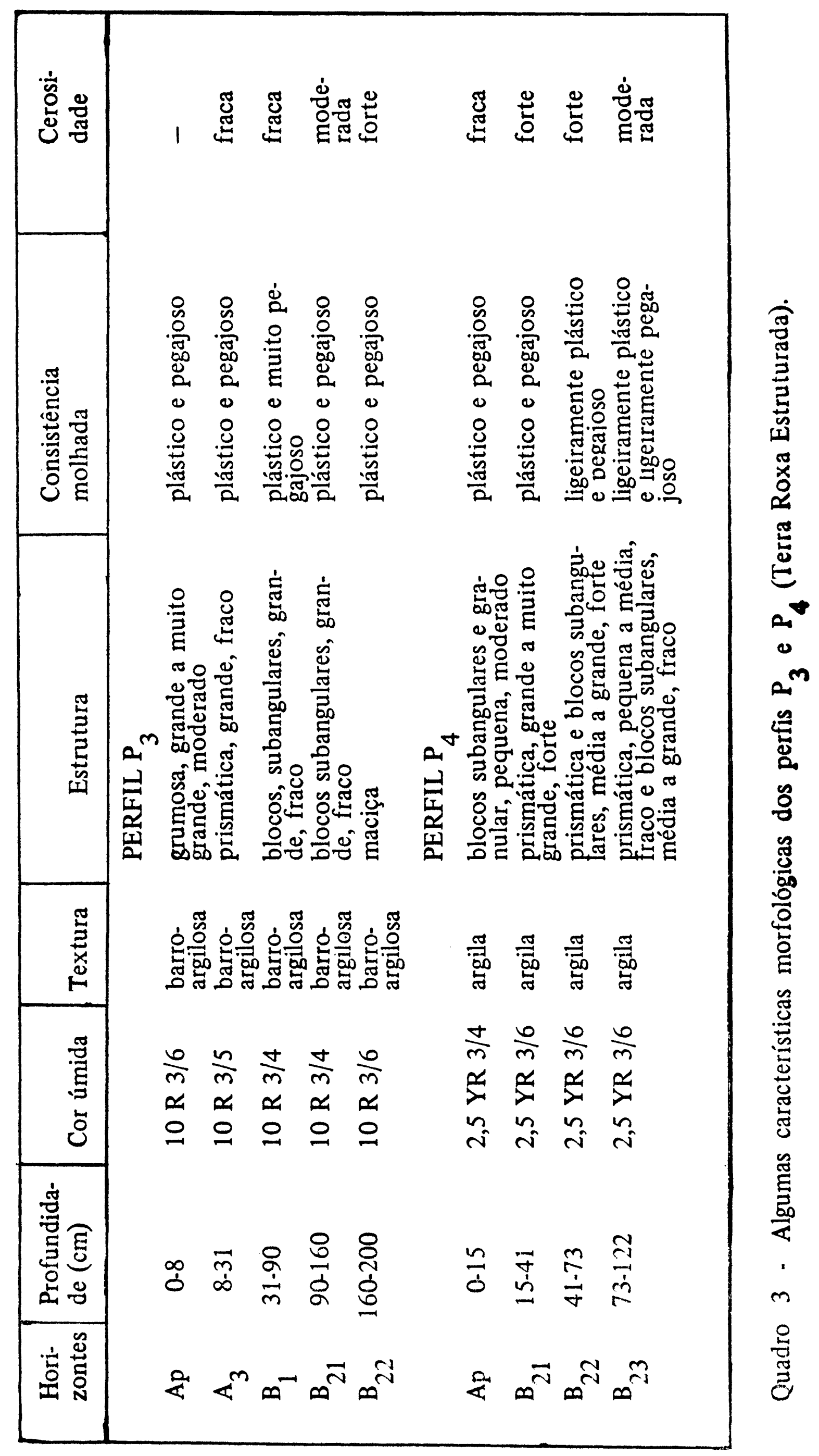




\section{Métodos}

\section{Coleta das amostras}

Para a coleta das amostras foram abertas trincheiras de $2 \mathrm{~m}$ le profundidade. A delimitação dos horizontes foi feita através de suas características diferenciais, tendo a morfologia obedecido às recomendações de RANZANI (1968).

As amostras indeformadas foram coletadas por horizonte e em duplicata. Horizontes com mais de $30 \mathrm{~cm}$ de espessura foram subdivididos, e cada uma destas, amostradas separadamente.

\section{Preparo das amostras para impregnação}

As amostras foram modeladas como cilindros de aproximadamente $4 \mathrm{~cm}$ de altura por $3 \mathrm{~cm}$ de diâmetro, sendo deixadas secar ao ar por 24 horas mais ou menos. A seguir, por outras tantas foram colocadas em estufa a $60-80^{\circ} \mathrm{C}$ para que a umidade restante fosse eliminada o mais possível, facilitando assim a penetração e polimerização da resina.

As amostras numeradas e assim preparadas foram colocadas nos frascos de vidro.

\section{Impregnação} (1973).

$O$ método usado aqui foi aquele proposto por TEIXEIRA MENDES et al

\section{Preparo das secções delgadas}

O corte, montagem, desgaste e polimento das amostras foi realizado segundo os padrões convencionais da técnica de preparo de secções delgadas e conforme descrito por TEIXEIRA MENDES et al (1973).

\section{Análise óptica}

As lâminas foram examinadas sob microscópio petrográfico unicamente com respeito às cutans.

Seguindo-se as recomendações de BREWER (1964), observaram-se:

(a) a natureza da superfície sobre a qual se depositaram: grânulo agregado ou vazio.

(b) o modelo de orientação: forte, moderada ou fraca.

(c) o grau de separação, que trata do grau de contraste entre o material cutânico e o não-cutânico do solo, e mencionado como: ligeira, fraca, moderada e fortemente separado. 


\section{RESULTADOS E DISCUSSÁO}

As observações feitas, sob microscópio petrográfico das lâminas de solo em secções delgadas, são aqui apresentadas e discutidas nas diversas subdivisões do horizonte $\mathrm{B}$ de cada um dos perfis.

\section{Perfil $\mathbf{P}_{1}$}

$\mathrm{O}$ exame das diversas lâminas do horizonte $\mathrm{B}_{21}$ evidenciou a presença de material com características diferentes daquelas da matriz desse horizonte, e conforme será discutido adiante, muito provavelmente originário de iluviação. Como tal material achava-se recobrindo elementos do solo, foi considerado como cutânico.

A foto 1 mostra o capeamento de agregados por cutans, tirada da parte superior do horizonte $B_{21}$, onde se nota a delgacidade das mesmas. Por outro lado, a apresentação pelas mesmas, de forte grau de separação com a matriz e também de forte orientação, levou a que fossem enquadradas como provenientes de iluviação, pois segundo BREWER (1964), estas duas últimas características são fortemente diagnósticas de material coloidal que foi colocado em suspensão, transportado e redepositado. Também FREI \& CLINE (1949) e McCALEB (1954) estabeleceram que a aparência em camadas dos minerais de argila continuamente orientados ao longo das paredes de poros, fendas e canais de raízes, constituem boa evidência do movimento físico das argilas dos horizontes superiores para a zona de máximo acúmulo de argila. Da mesma forma, SMECK et al (1968) citaram que a característica mais proeminente do horizonte $\mathrm{B}_{23^{\mathrm{t}}}$ nos solos Morley e Celina em Ohio, Estados Unidos, era a abundância de cutans iluviais com forte grau de separação com a matriz e forte orientação.

A foto 2 , tirada da parte inferior do horizonte $B_{21}$ também mostra as cutans capeando os agregados.

Esta delgacidade das cutans iluviais não causou muita surpresa porque apesar de terem uma porosidade elevada, os latossóis normalmente apresentam uma pequena eluviação devido as suas próprias características físicas: as argilas em geral estão, ou floculadas ou formando microagregados de difícil eluviação.

Por outro lado, o serem as cutans iluviais descontínuas, isto é, não estarem capeando totalmente os agregados ou vazios, sugere que, sendo este horizonte bastante próximo da superfície, está sujeito às perturbações inerentes à posição no perfil tais como: pressões por penetração de raízes e perturbações na massa do solo provocadas pela fauna e manejo. Fatos semelhantes já foram relatados por diversos autores (BUOL \& HOLE, 1961; SMECK et al, 1968; PETTAPIECE \& ZWARICH, 1970) que atribuíram a descontinuidade das cutans iluviais em horizontes superficiais, pelo menos em parte, a fatores como: forças de expansão e contração devidas ao molhamento e secagem e (ou) congelamento e degelo e, pressões de raízes, que são maiores perto da superfície e decrescem com a profundidade. Como BUOL \& HOLE (1961) sugeriram, tais perturbações poderiam gerar o quebramento de ve- 


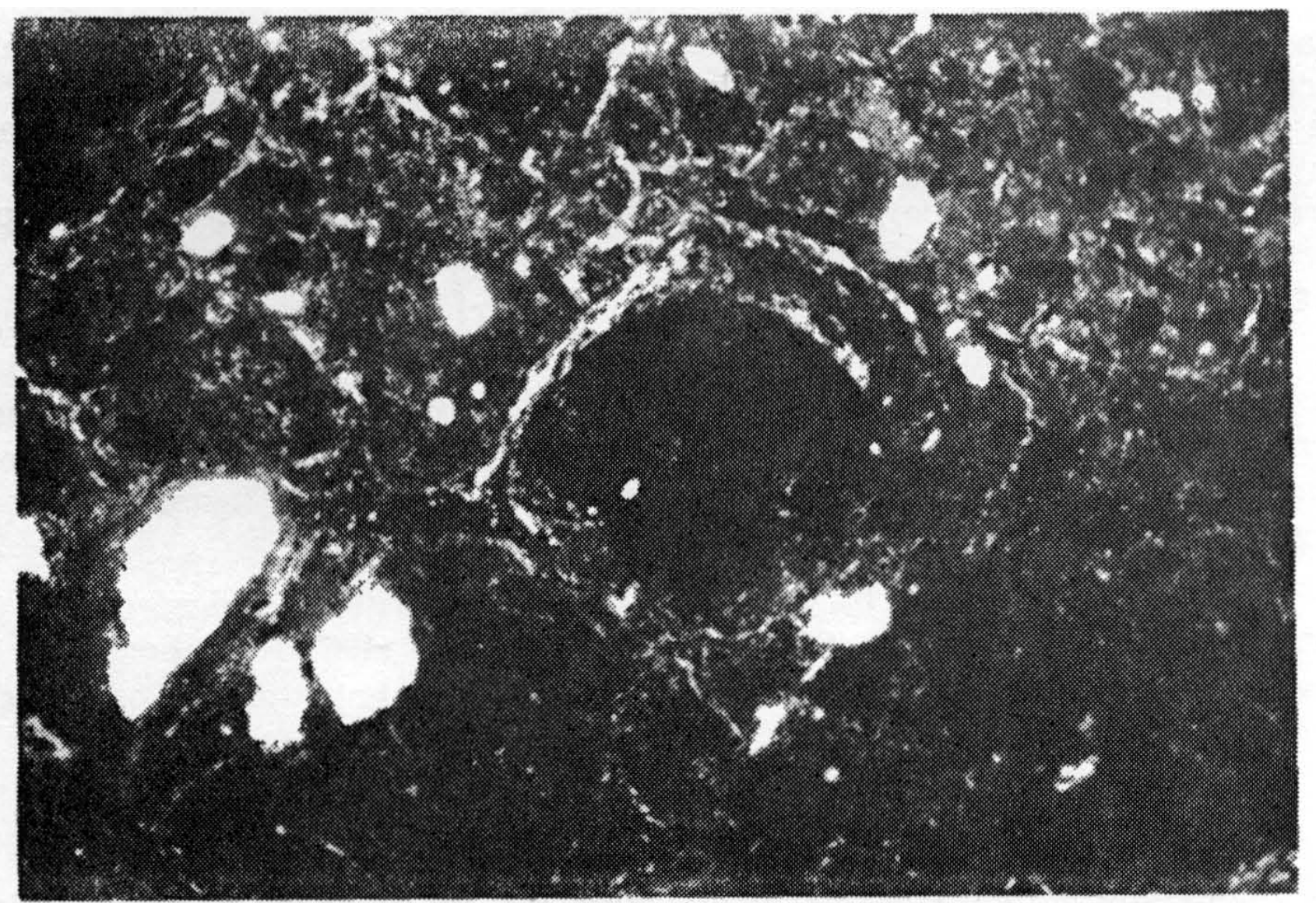

FOTO 1. Cutans capeando agregados. Parte superior do horizonte $B_{21}$, perfil $P_{1}$. Polarizadores cruzados, $114 \times$.

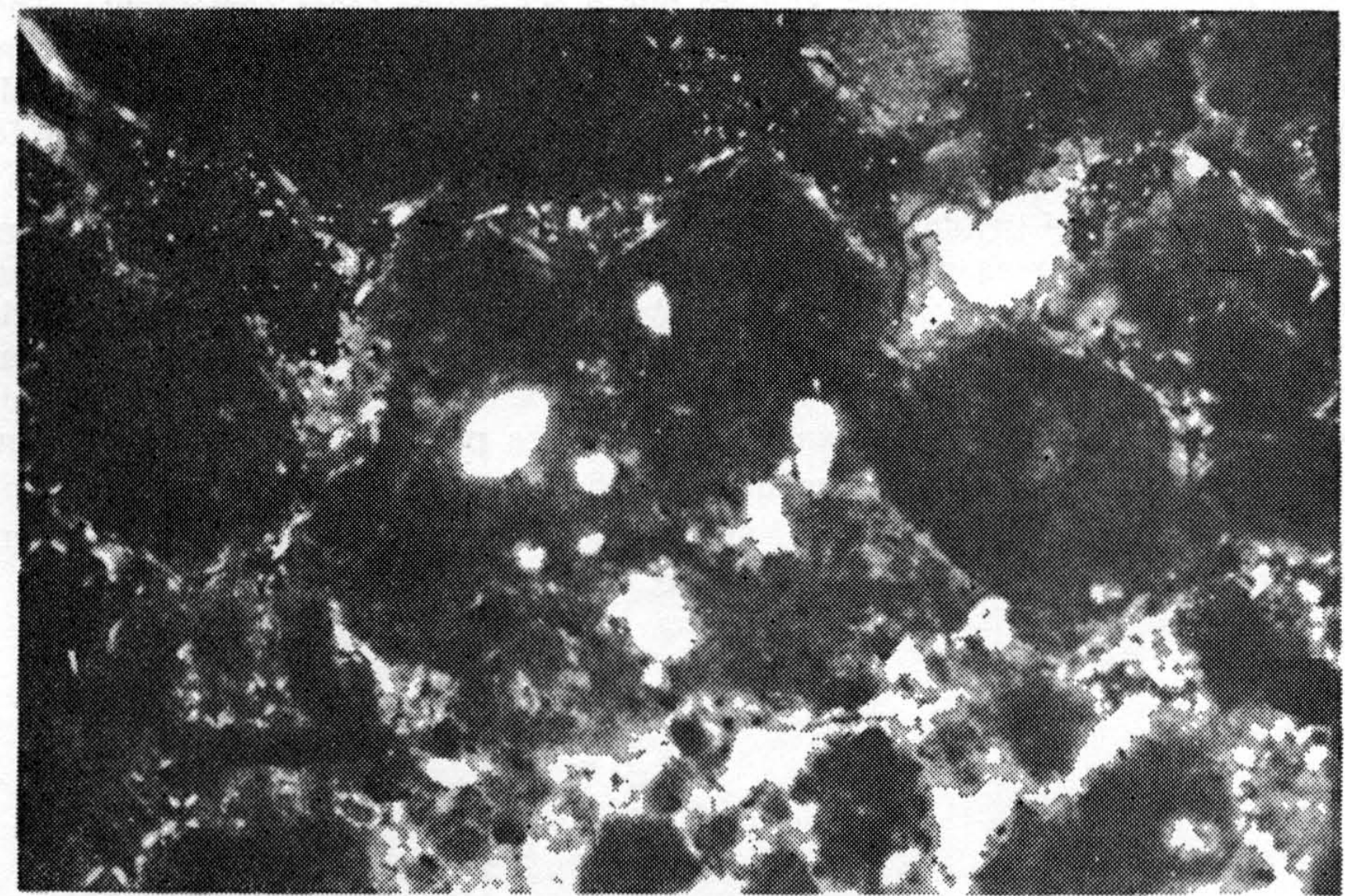

FOTO 2. Cutans capeando agregados. Parte inferior do horizonte $B_{21}$, perfil $P_{1}$. Polarizadores cruzados, $114 \mathrm{x}$. 
lhos agregados e a formação de novos, que incorporariam o material cutânico, acumulado nas paredes de vazios e sobre os agregados, dentro de si. Já PETTAPIECE \& ZWARICH (1970) atribuíram o aumento da densidade da matriz dos agregados na parte superior do horizonte Btr dos solos Orthic Grey Wooded (Podzólico) e Orthic Dark Grey (Chernozem degradado) por eles estudados, à formação de agregados com cutans incorporados devido às perturbações na massa do solo.

Segundo o SOIL SURVEY STAFF (1967) uma das características principais do horizonte argílico é a presença de concentrações de argila orientada provenientes de iluviação. Portanto, a presença de cutans iluviais neste hozizonte $B_{21}$ e a espessura destc, superior a $15 \mathrm{~cm}$, sugerem a formação de um argílico.

Os horizontes $\mathrm{B}_{22}$ e $\mathrm{B}_{23}$ apresentaram-se inteiramente desprovidos de cutans, e, ainda segundo o SOIL SURVEY STAFF (1967), um horizonte no qual as cutans estejam ausentes, é forte indicação, entre outras características, de um horizonte óxido.

\section{Perfil $\mathbf{P}_{2}$}

Bem como para o correspondente horizonte $B_{21}$ do perfil $P_{1}$, observou-se uma certa diferença entre a quantidade das cutans nas partes superior e inferior do horizonte: a quantidade de cutans presentes na parte superior era menor que a da parte inferior, se bem que a espessura fosse semelhante. Anotou-se também para a parte superior deste horizonte; a presença de cutans consideradas delgadas, como pode ser visto na foto 3 . No entanto, aquela descontinuidade observada para essa mesma parte no perfil $P_{1}$ não o foi neste perfil $\mathrm{P}_{2}$.

Nas fotos 3 e 4 tiradas da parte superior do horizonte $B_{21}$, podem-se notar as cutans forrando as paredes de vazios e capeando agregados, respectivamente. Percebe-se também que a aparência das cutans é completamente diferente daquela do material por elas envolvido, e por esse motivo foi considerado como forte o grau de separação da mesma com a matriz. À medida que, com os polarizadores cruzados, girava-se a platina do microscópio, percebiam-se claramente as faixas de extinção da cutan percorrerem-na, típicas de polarização de agregados, sendo por esse motivo, o modelo de orientação da cutan considerado como forte. 


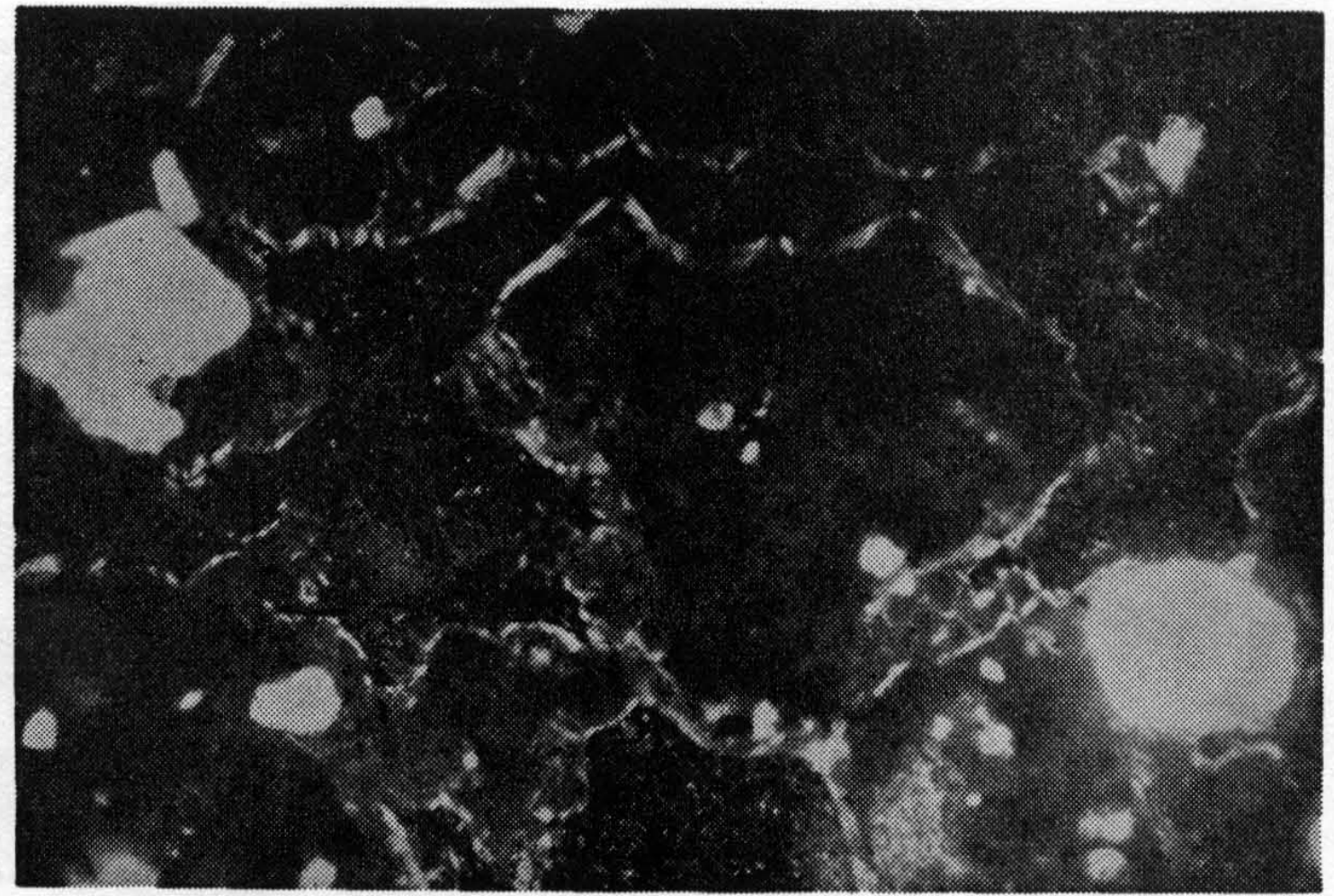

FOTO 3. Cutans forrando vazio na parte superior do horizonte $B_{21}$, perfil $P_{2}$. Polarizadores cruzados, $114 \times$.

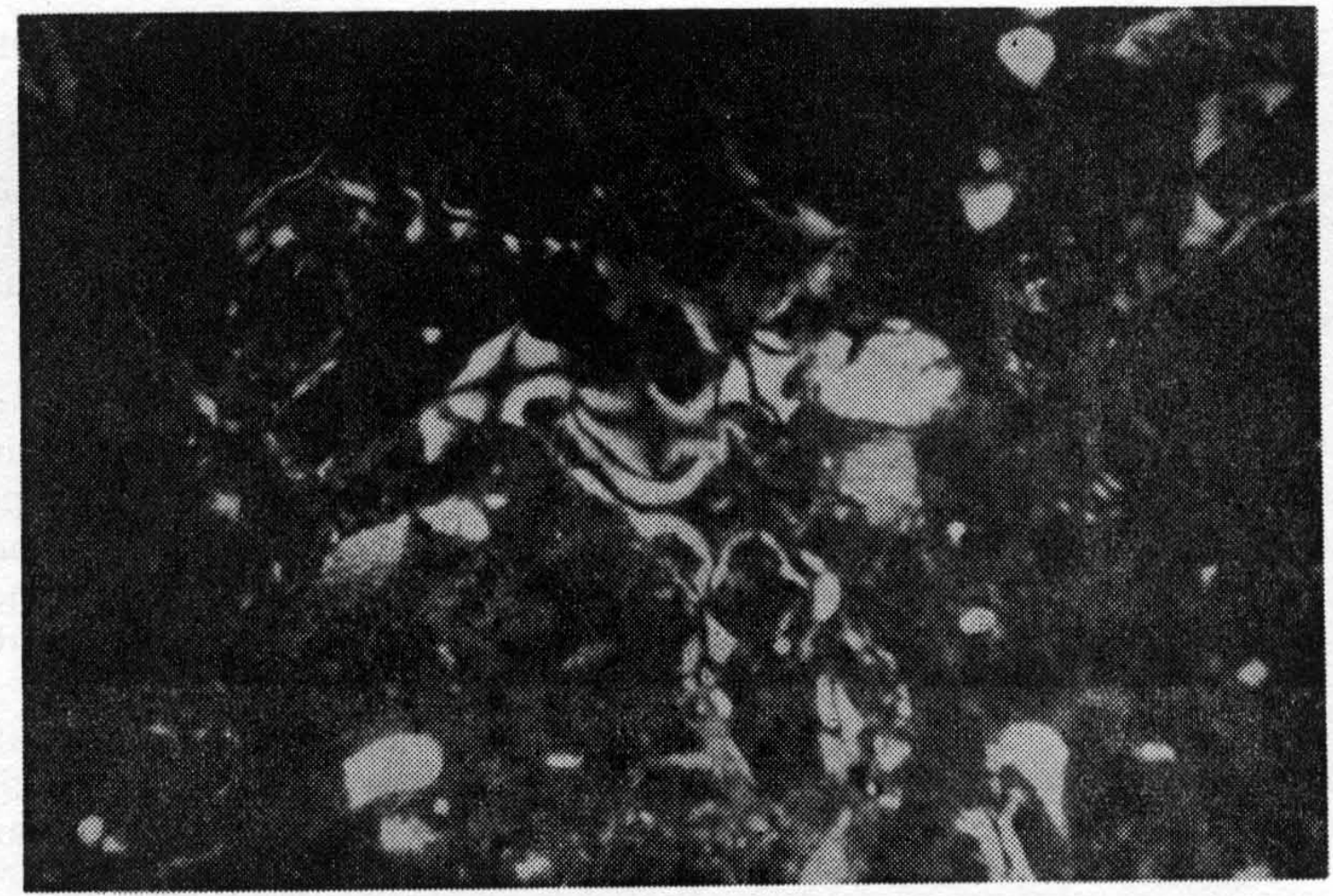

FOTO 4. Cutans capeando agregados na parte superior do horizonte $B_{21}$, perfil $P_{2}$. Polarizadores cruzados, $114 x$. 
A foto 5 mostra os agregados sendo totalmente envolvidos pelas cutans, tirada da parte inferior do horizonte $B_{21}$.

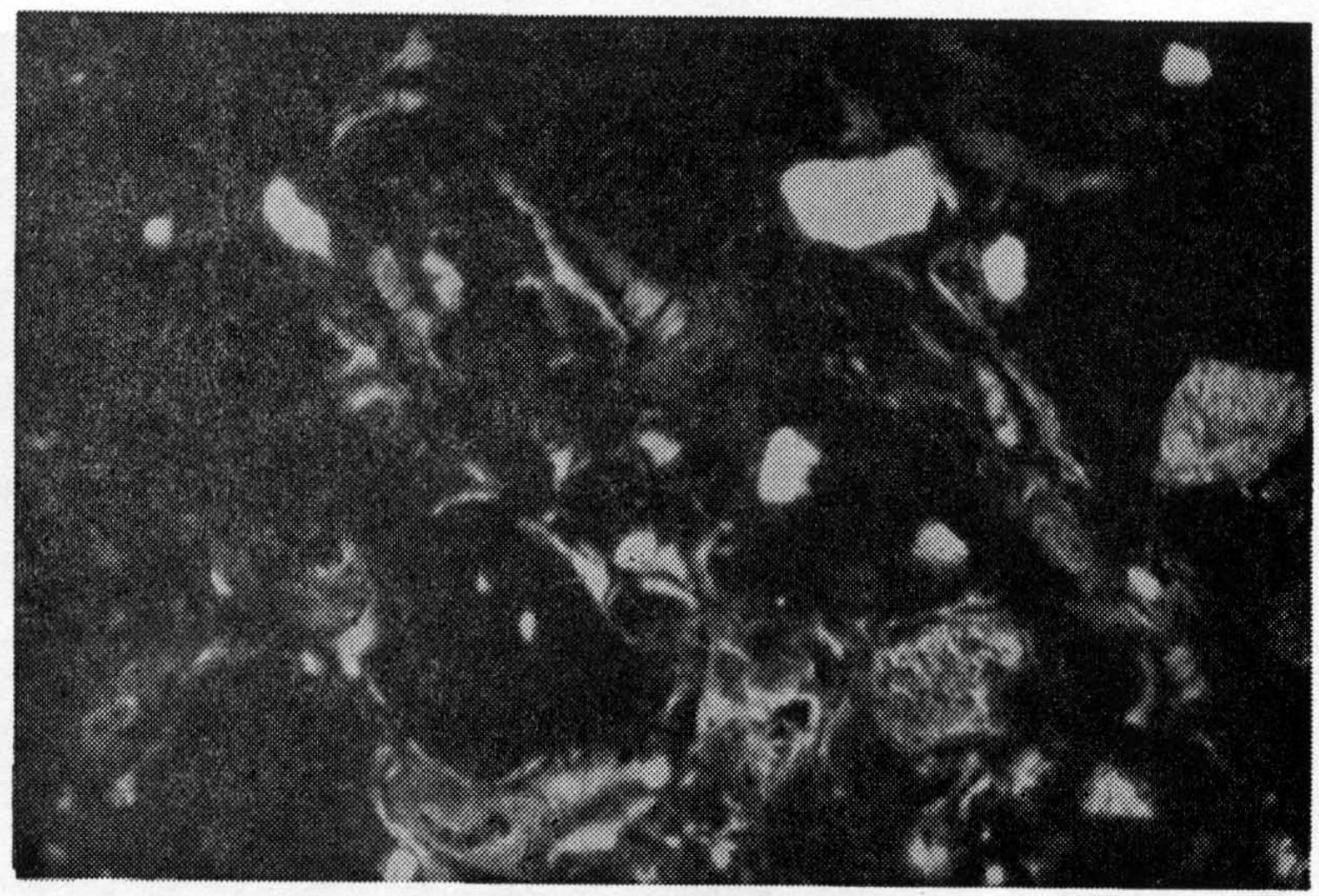

FOTO 5. Cutans envolvendo agregados. Parte inferior do horizonte $B_{21}$, perfil $\mathbf{P}_{2}$. Polarizadores cruzados, $114 \mathrm{x}$.

$O$ estudo do horizonte $B_{21}$ revelou que, indubitavelmente este horizonte recebeu farta contribuição de material eluviado dos superiores. Esta observação foi deduzida através das secções delgadas que mostraram cutans iluviais que praticamente preenchiam todos os vazios entre os agregados. Aliada às propriedades que denotam o caráter iluvial da cutan, notou-se marcantemente a espessura das mesmas, que não só permitiu-lhes capear como interligar os agregados.

Pode-se postular que a não observância de descontinuidade das cutans na parte superior do horizonte $B_{21}$ seja devida por estar o perfil $\mathrm{P}_{2}$ numa situação de meia encosta e portanto sujeito às perdas inerentes à sua posição topográfica, acentuadas ainda pelo sistema de manejo em cultivo praticamente anual. Assim, aquela parte do horizonte textural sob a influência de tais condições já teria sido removida, restando um novo horizonte ainda não perturbado. Deste modo, se fossem anotadas no atual horizonte Ap a presença de cutans, cujas características denotassem serem elas iluviais, tal hipótese teria comprovação. A foto 6 , tirada do horizonte Ap, evidencia claramente a presença de cutans iluviais, suportando pois a hipótese levantada.

$O$ fato de serem mais delgadas as cutans iluviais presentes na parte superior do horizonte $B_{21}$ sugere que estas possam estar sendo carreadas para a parte mais inferior, onde é bem maior a espessura das mesmas. 
Tem-se notado ainda, que para os Latossóis Roxos que apresentam um horizonte argílico incipiente, à medida que se desce no relevo e mais próximo ao material de origem do solo, há um aumento da expressividade desse B argílico (comunicação do professor Dr. José Luís Ioriatti Demattê, ESALQ). Assim, o ter-se encontrado uma quantidade de cutans muito maior no perfil $\mathrm{P}_{2}$ que no $\mathrm{P}_{1}$ pode ser deduzida do fato de o primeiro achar-se em uma posição mais baixa na topossequência e portanto mais junto ao material originário.

Também os horizontes $B_{22}$ e $B_{23}$, assim como os correspondentes do perfil $P_{1}$, não apresentaram cutans, enquadrando-se ambos nas características de um horizonte óxico.

\section{Perfil $\mathbf{P}_{3}$}

A cerosidade do horizonte $\mathrm{B}_{1}$, descrita morfologicamente no quadro 3 , como fraca, revelou-se nas secções delgadas como espessas cutans capeando agregados e delineando vazios tais como canais e poros.

Assim, na foto 7 observam-se cutans capeando as paredes de um extenso canal. Sendo, o grau de separação com a matriz e a orientação fortes, pelas razões já citadas foram tais cutans enquadradas como iluviais.

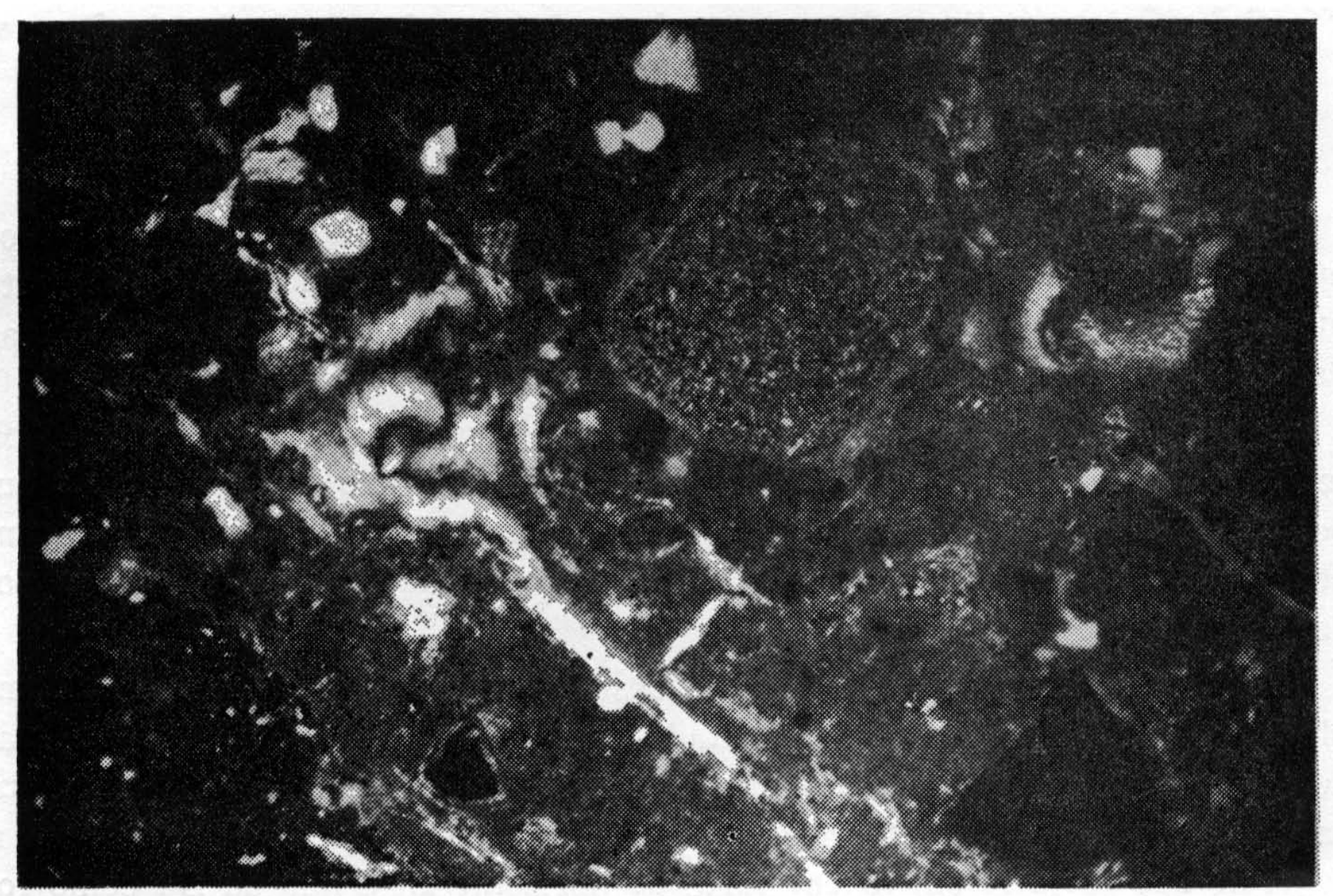

FOTO 6. Cutans no horizonte Ap, perfil $P_{2}$. Polarizadores cruzados $114 \mathrm{x}$. 


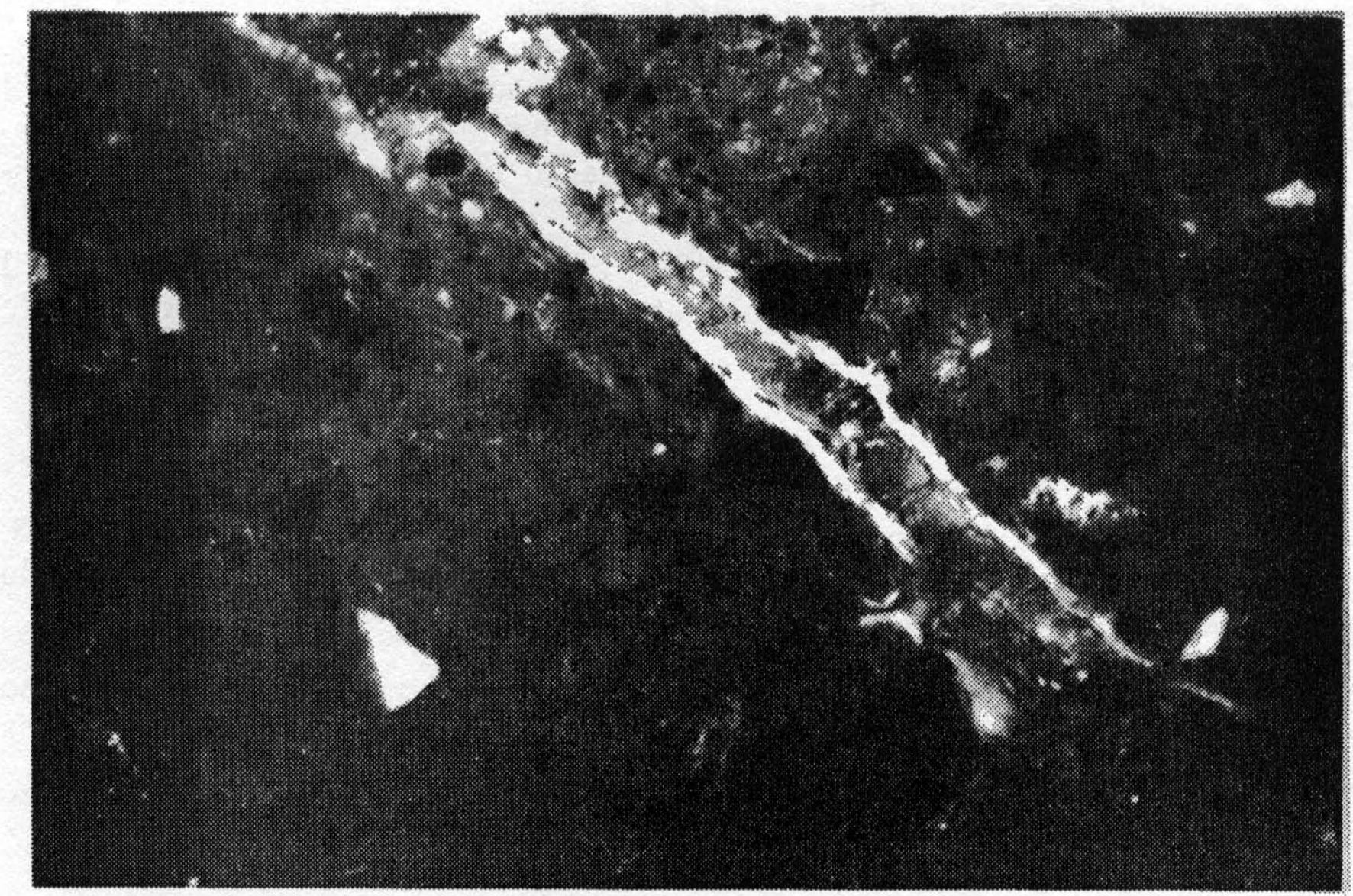

FOTO 7. Cutans delineando um canal, parte superior do horizonte $\mathbf{B}_{1}$, per fil $P_{3}$. Polarizadores cruzados. $114 \times$.

A foto 8 mostra um grande e irregular vazio totalmente revestido por cutans iluviais. A foto 9, tirada de uma posição mais inferior deste horizonte mostra cutans capeando agregados, apresentando as mesmas características daquelas da parte superior do horizonte.

No estudo do horizonte $B_{21}$ notou-se que, apesar de a análise morfológica ter descrito cerosidade em grau moderado, somente naquela parte mais superior do horizonte (primeiros $10 \mathrm{~cm}$ ), em contato com o horizonte $B_{1}$, foram detectadas cutans. Assim, na foto 10, cutans capeando alguns agregados podem ser vistas.

Todas as lâminas da outra parte deste horizonte $B_{21}$ revelaram a completa ausência de cutans. Tal resultado pode ser explicado da seguinte maneira: como o $B_{1}$ apresenta grande teor de cutans iluviais, a presença desta característica na parte superior do horizonte $B_{21}$ (primeiros $10 \mathrm{~cm}$ ), leva a sugereir que estes $10 \mathrm{~cm}$ fazem parte do horizonte $B_{1}$ e não do $B_{21}$ como foi anotado na descrição morfológica. 


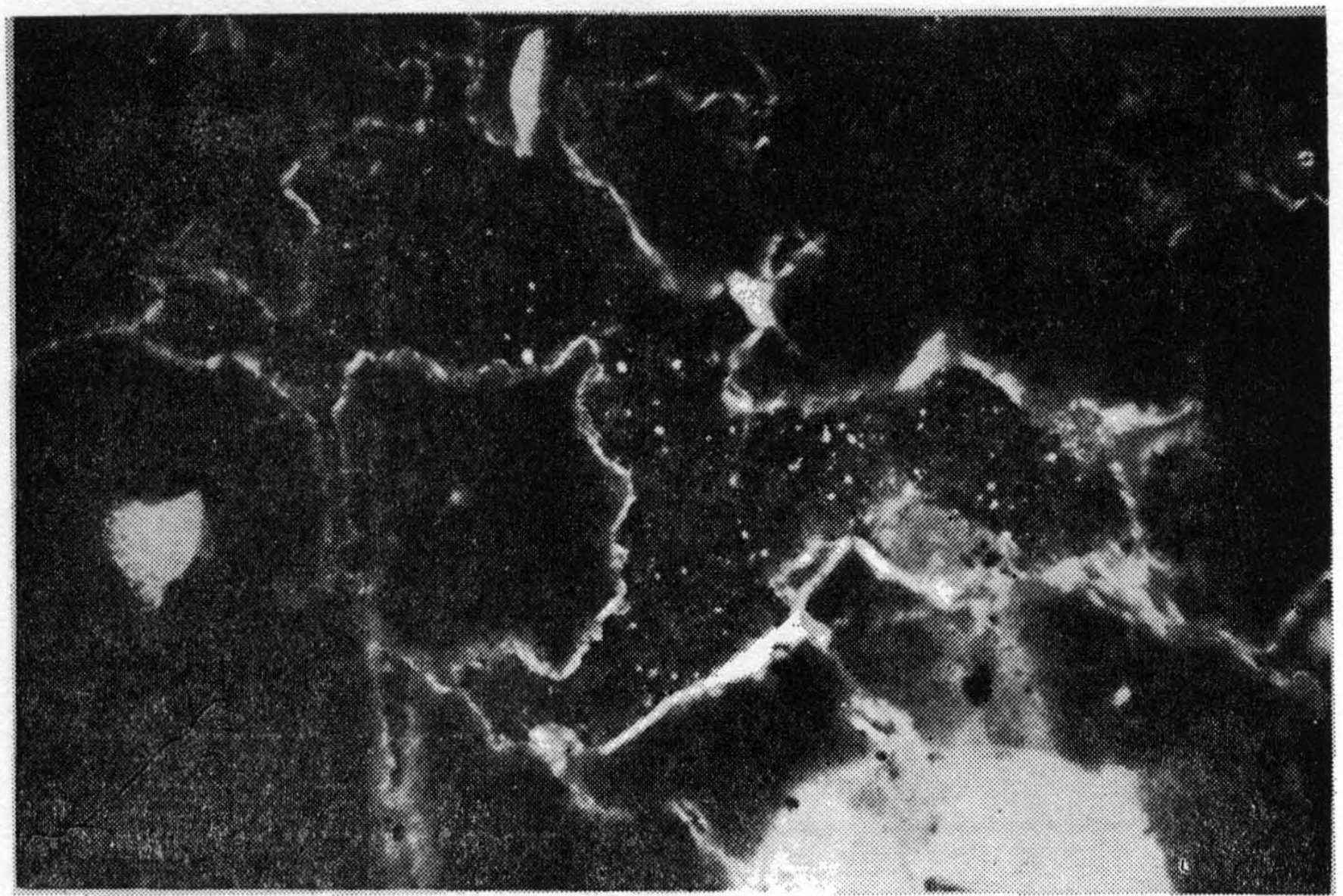

FOTO 8. Cutans revestindo um vazio irregular, na parte superior do horizonte $B_{1}$, perfil $P_{3}$. Polarizadores cruzados $114 \mathrm{x}$.

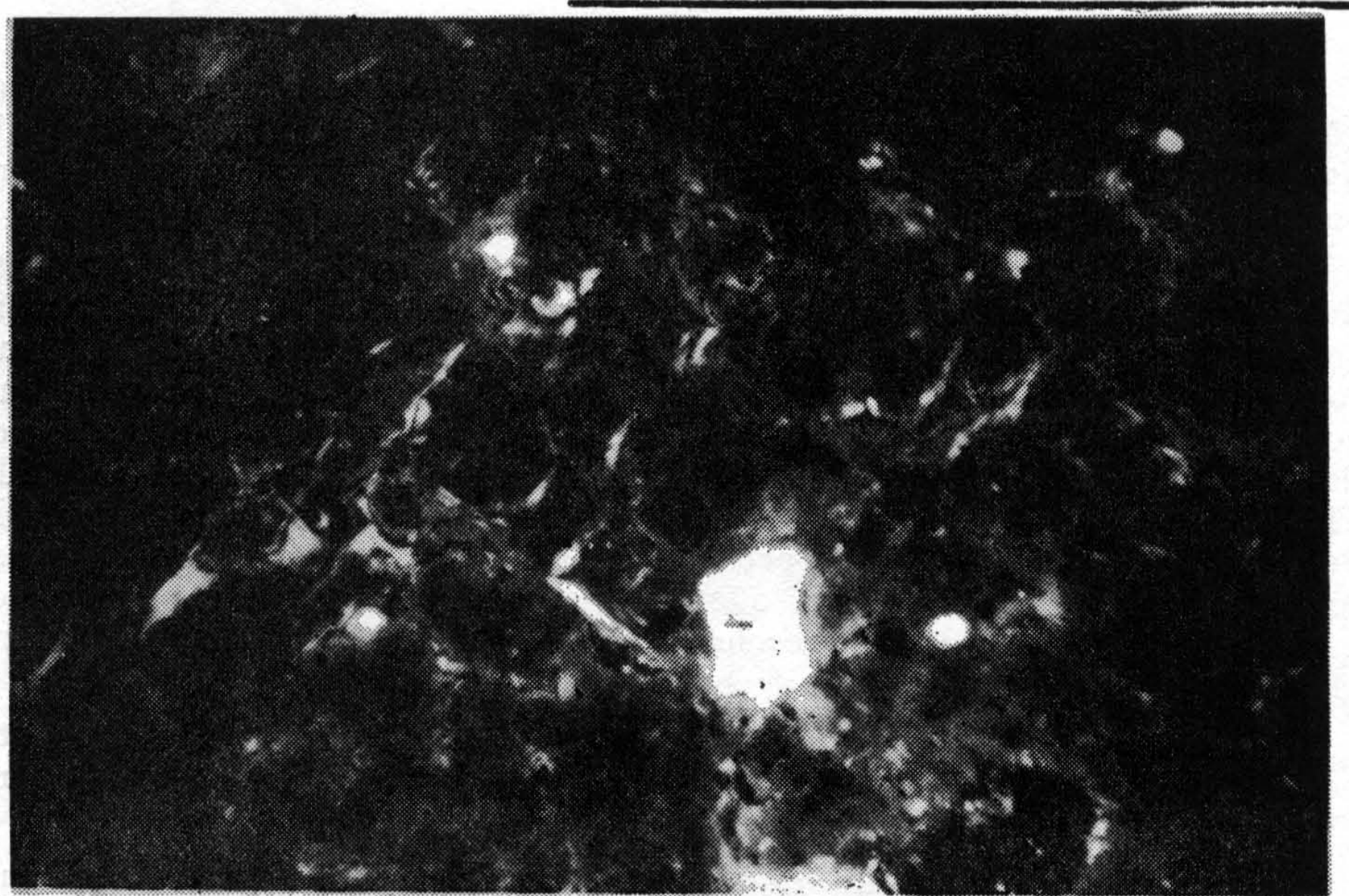

FOTO 9. Cutans capeando agregados. Parte inferior do horizonte $B_{1}$, perfil $P_{3}$. Polarizadores cruzados $114 \mathrm{x}$. 


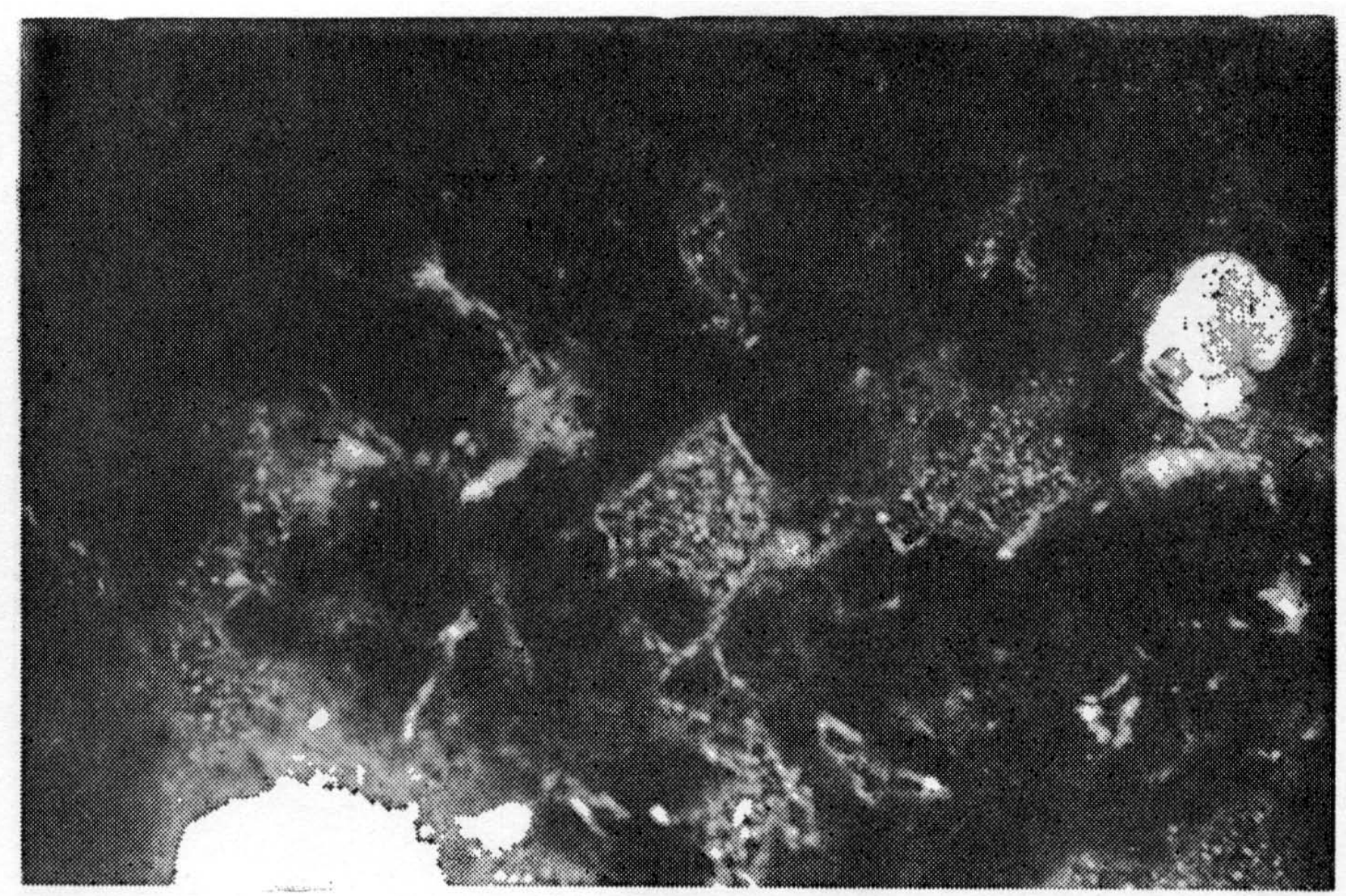

FOTO 10. Cutans capeando agregados. Parte superior do horizonte $\mathbf{B}_{21}$, perfil $P_{3}$. Polarizadores cruzados, $114 \times$.

A presença de grande quantidade de cutans, observadas através das secções delgadas no horizonte $B_{1}$, demonstra que o mesmo possui muito mais as características de um $\mathrm{B}_{2}$ t típico do que aquelas de um horizonte de transição. Neste caso, tal denominação de $B_{1}$ deveria ser eliminada.

As secções delgadas do horizonte $B_{22}$ mostraram que não havia cutans. Tal fato discorda completamente das observações feitas na descrição morfológica deste horizonte que descreveu a presença de cerosidade em grau forte. Como fatores que podem ter induzido a que se detectasse no campo uma cerosidade cuja não existência foi comprovada micromorfologicamente, podem-se citar a umidade e o material coloidal não transportado. Como NETTLETON et al (1969) relataram, corpos de argila orientada em horizontes B de textura média e fina podem erroneamente ser confundidos com as cutans. As observações feitas sugerem que isto pode ter ocorrido neste horizonte, e também confirmam que a presença de iluviação deve ser comprovada em laboratório através da técnica do estudo do solo em secções delgadas.

Dos resultados obtidos pôde-se deduzir que, as cutans presentes neste perfil $\mathrm{P}_{3}$ são de natureza iluvial e bastante expressivas, isto é, houve significativa iluviação de material coloidal.

A presença de cutans até os primeiros centímetros do horizonte $B_{21}$ sugeriu que o argílico atinge até esse ponto do perfil, englobando o horizonte $\mathrm{B}_{1}$ e esses primeiros centímetros do $\mathrm{B}_{21}$. 
A ãusência de cutans, entre outras características que não cabem ser aqui discutidas, sugerem que após os primeiros centímetros do horizonte $B_{21}$, inicia-se um horizonte óxico, que se continua através do $B_{22}$ também desprovido de cutans.

\section{Perfil $\mathbf{P}_{4}$}

A presença de cutans no horizonte $B_{21}$ deste perfil foi registrada muito mais frequentemente forrando as paredes de vazios do que como capeamentos dos agregados.

Além disso, ao contrário do que se verificou para os demais perfis, a diferença registrada para as partes superior e inferior do horizonte $B_{21}$, manifestou-se pela maior quantidade de cutans na parte superior em vez de aparecerem na inferior, se bem que a espessura das mesmas não mostrasse diferença.

Examinando-se a parte superior do horizonte $B_{21}$ notou-se que as cutans eram delgadas, e como se pode ver na foto 11 achavam-se delineando as paredes de vazios. Nessa mesma foto vêem-se dois pequenos vazios que se achavam praticamente obstruídos pelas cutans.

Já na parte inferior deste mesmo horizonte, as cutans, além de delgadas apresentavam-se em pequena quantidade. $\mathrm{Na}$ foto 12 vêem-se finas cutans forrando as paredes de pequenos vazios.

A apresentação de forte grau de separação com a matriz e forte orientação conduziu, como já se notou anteriormente, a que fossem colocadas como cutans iluviais.

$O$ exame do horizonte $B_{22}$ revelou que a presença das cutans no mesmo manifestou-se uniformemente, tanto nas partes superior como inferior, e também que quanto à espessura, mostraram-se semelhantes às do horizonte $B_{21}$. A foto 13 mostra cutans bem delgadas ao redor de agregados e em vazios, tirada da parte superior do horizonte, enquanto que a 14 mostra um aspecto semelhante somente que da parte inferior.

A não existência de cutans no horizonte $B_{23}$, contrariando pois a descrição morfológica, foi comprovada através de diversas lâminas.

Da análise dos dados apresentados por este perfil, ressalta à primeira vista o que parece ser uma incoerência com o já exposto anteriormente: aquela parte superior do horizonte $B_{21}$ que habitualmente apresentava-se com uma quantidade de cutans menor, e sendo estas descontínuas e esparsas, mostrou-se neste perfil como possuidora de cutans em maior quantidade que a parte inferior do horizonte e também com uma continuidade que não era peculiar. 


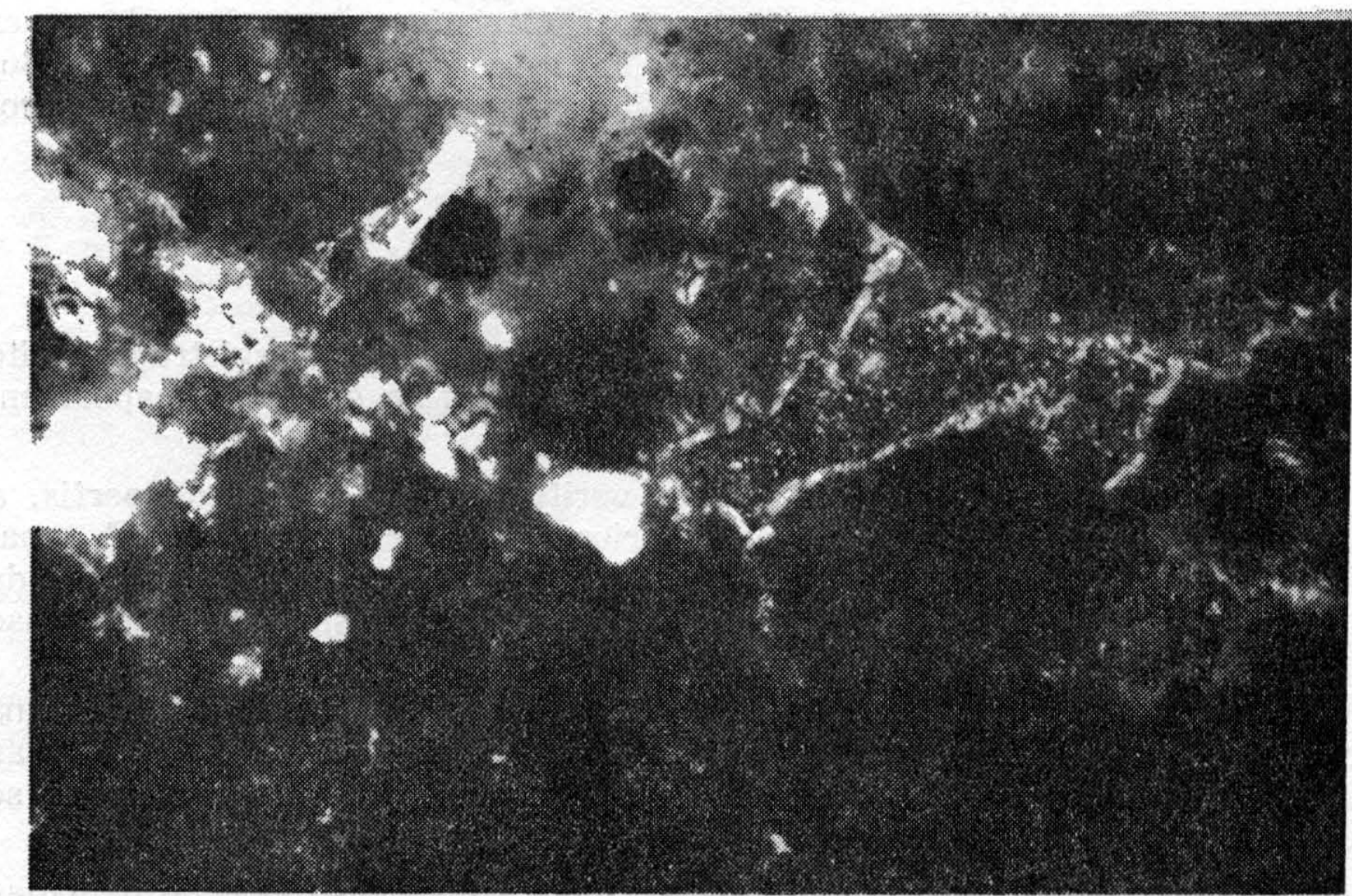

FOTO 11. Cutans delineando vazios. Parte superior do horizonte $\mathbf{B}_{21}$, perfil $P_{4}$. Polarizadores cruzados, $114 \times$.

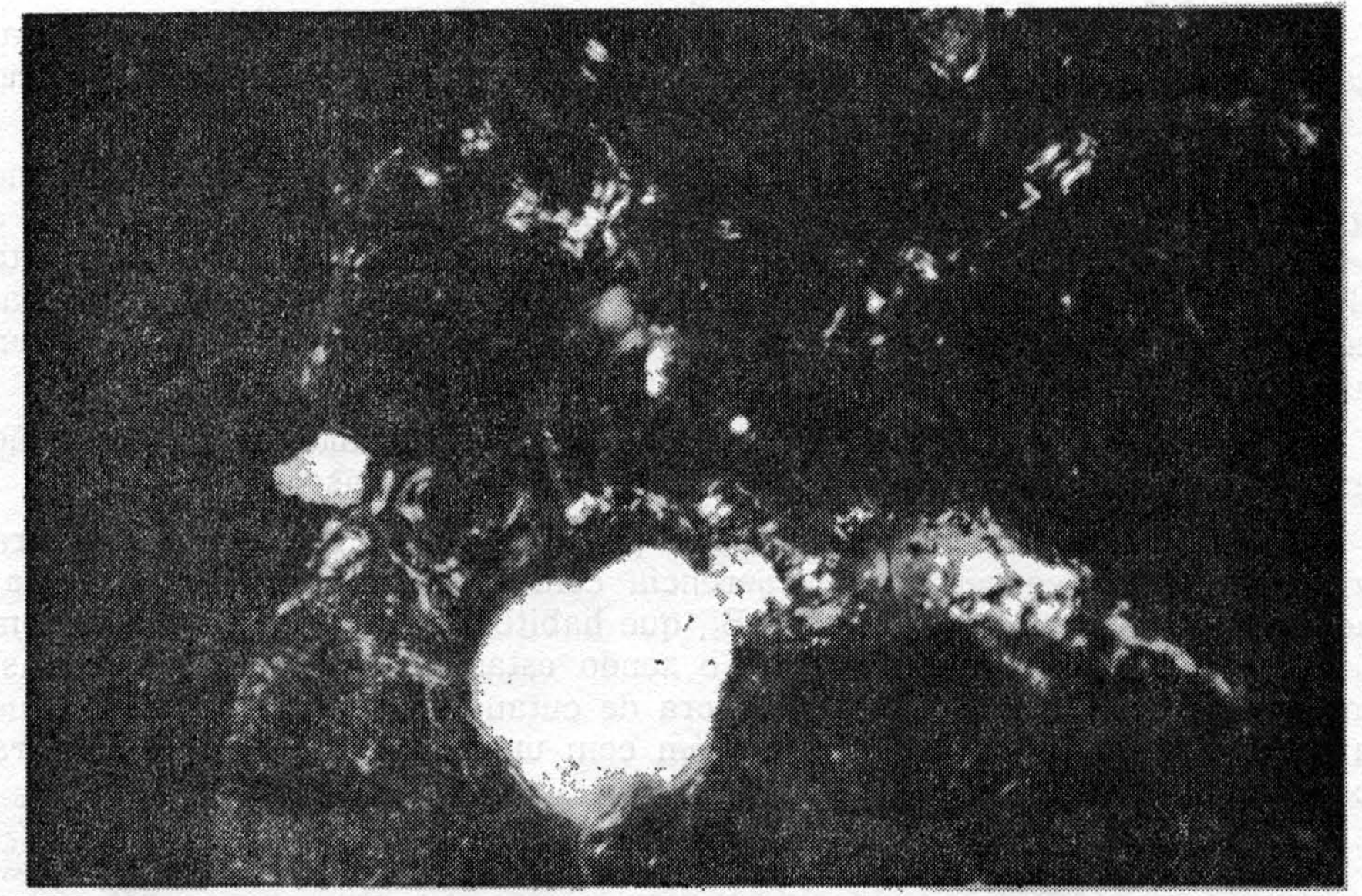

FOTO 12. Cutans delgadas delineando vazios. Parte inferior do horizonte $B_{21}$, perfil $P_{4}$. Polarizadores cruzados, $114 \times$. 


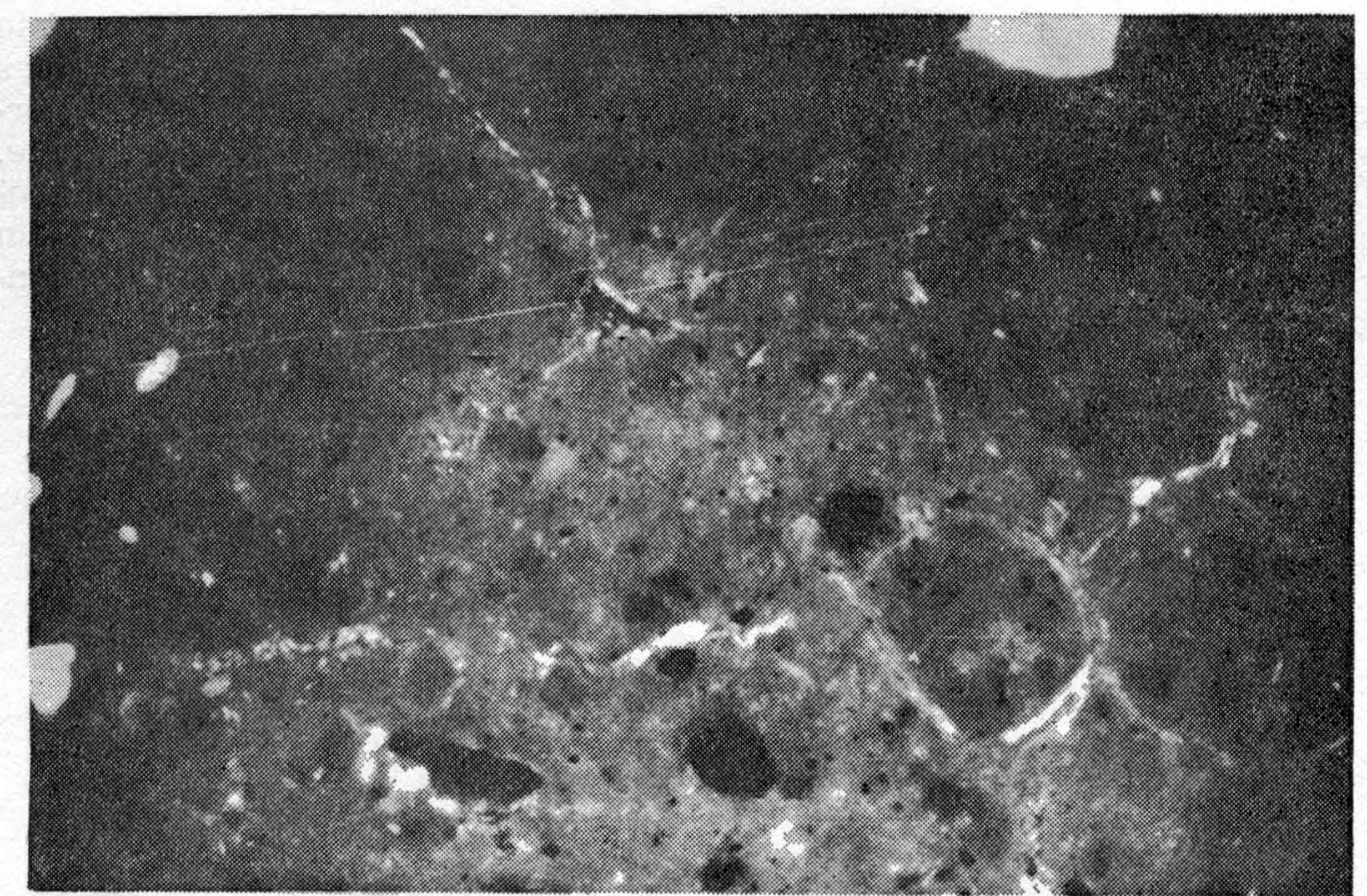

FOTO 13. Cutans capeando agregados e delineando vazios. Parte superior do horizonte $B_{22}$, perfil $P_{4}$. Polarizadores cruzados, $114 \mathrm{x}$.

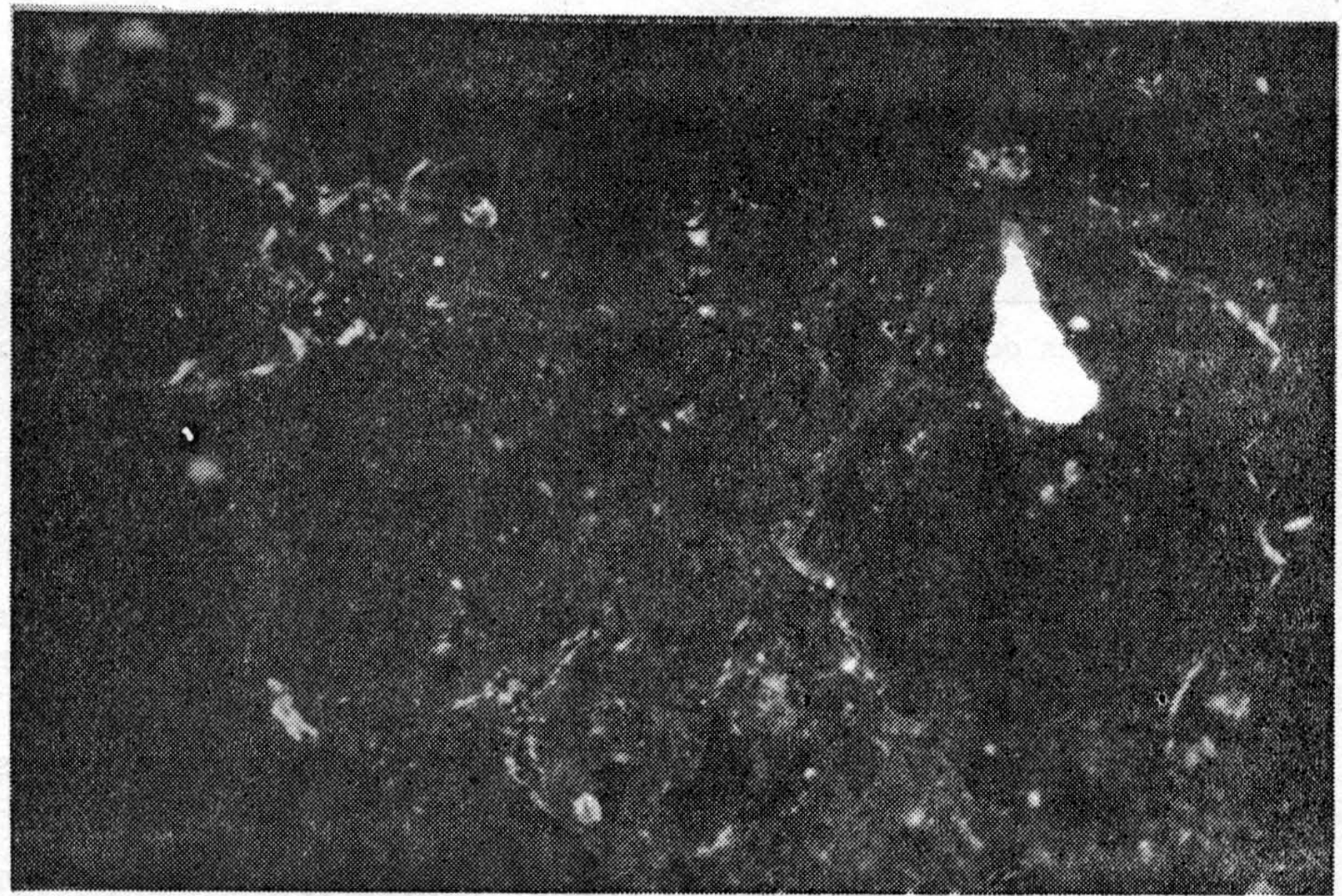

FOTO 14. Cutans capeando agregados. Parte inferior do horizonte $B_{22}$, perfil $P_{4}$. Polarizadores cruzados, $114 \times$. 
A verificação da situação topográfica do perfil elucidou tal fato, visto achar-se ele na parte mais baixa da encosta e por conseguinte sujeito as perdas por erosão. Supôs-se assim, que aquela parte superior do perfil normal já houvesses sido decapitada e portanto a parte superior do horizonte, a que exibiria uma menor quantidade de cutans que seriam também descontínuas, seria no momento, o atual horizonte Ap. O estudo deste horizonte em secções delgadas revelou a presença de cutans iluviais esparsas e em quantidade muito pequena, como pode ser deduzido no exame da foto 15.

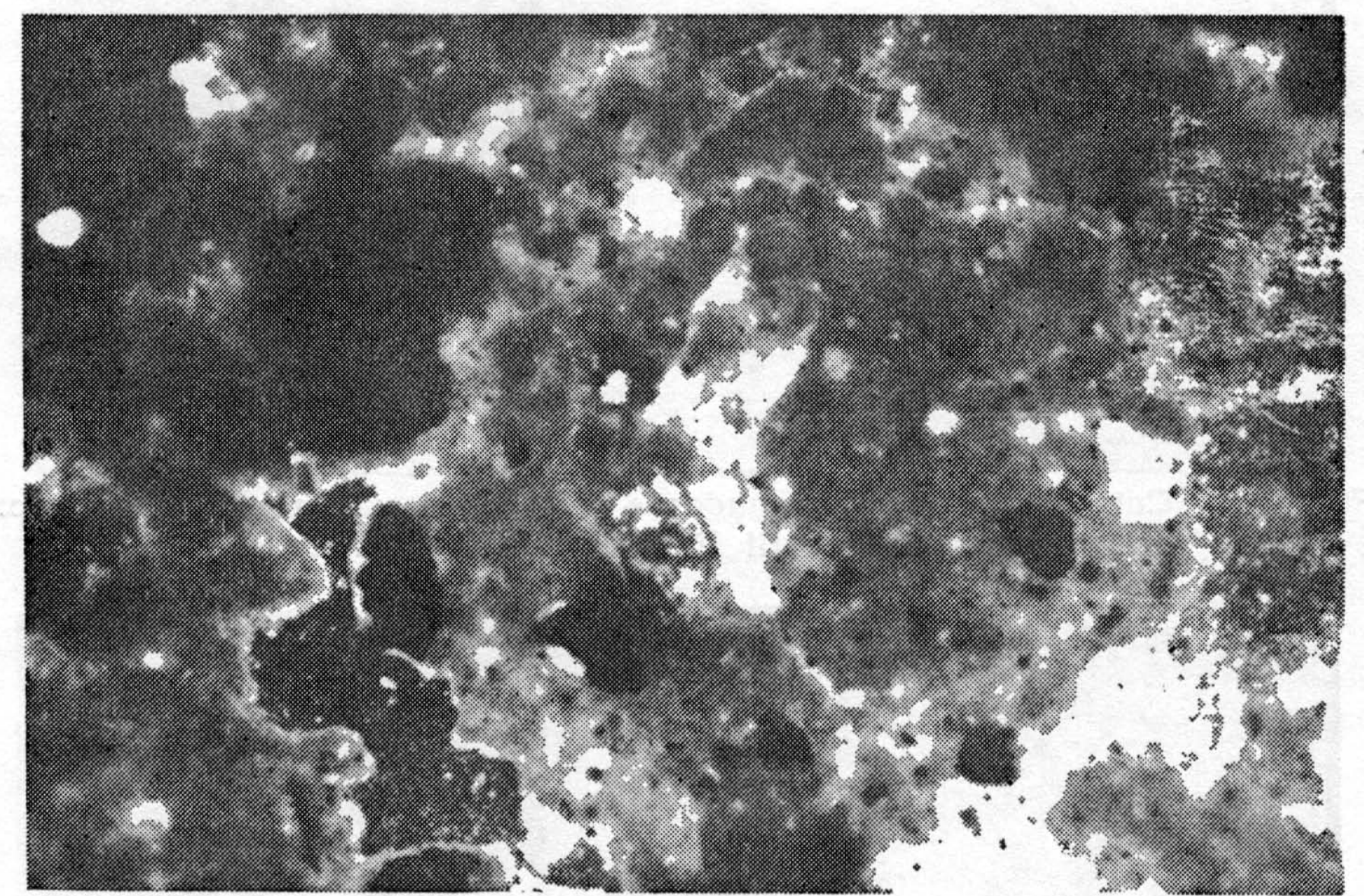

FOTO 15. Cutans do horizonte Ap, perfil $\mathbf{P}_{4}$. Polarizadores cruzados, 114 x.

\section{CONCLUSOES}

1. A descontinuidade das cutans na parte superior dos horizontes considerados como argílicos, sugeriu que estes estão sob a influência de condições desfavoráveis ao acúmulo de cutans.

2. As cutans encontradas nos quatro perfis estudados enquadram-se na classificação genética de BREWER (1964) como iluviais.

3. O horizonte argílico dos perfis $\mathrm{P}_{1}$ e $\mathrm{P}_{2}$ situa-se naquele descrito morfologicamente como $B_{21}$, enquanto que o do perfil $P_{3}$ engloba o horizonte $B_{1}$ e os primeiros $10 \mathrm{~cm}$ do $B_{21}$. Já no $P_{4}$, engloba o $B_{21}$ e o $B_{22}$. 
4. A presença de grande quantidade de cutans no horizonte $B_{1}$ do perfil $\mathrm{P}_{3}$ sugere que sua denominação deveria ser mudada para $\mathrm{B}_{2}$.

5. A detecção de cerosidade em grau forte na análise morfológica do horizonte $B_{22}$ do perfil $P_{3}$ sugere que isto tenha se devido a fatores como umidade e material coloidal não transportado.

\section{SUMMARY}

\section{IDENTIFICATION OF CUTANS IN PROFILES OF «LATOSSOL ROXO» AND «TERRA ROXA ESTRUTURADA».}

The purpose of this work was the study of cutans in two soil profiles of the Iracema series, Latossol Roxo Great Group, and two profiles of Terra Roxa Estruturada.

The study was based on the exam, under the petrographic microscope, of thin sections prepared from undisturbed soil samples taken from the main horizons of the four profiles under study.

The exam of the thin sections revealed the presence of illuvial cutans in the $B_{21}$ horizons of the Latossol Roxo (profiles $P_{1}$ and $P_{2}$ ), in the $B_{1}$ and part of the $B_{21}$ horizons of profile $P_{3}$ (Terra Roxa Estruturada) and int the $\mathrm{B}_{21}$ and $\mathrm{B}_{22}$ horizons of profile $\mathrm{P}_{4}$ (Terra Roxa Estruturada).

\section{LITERATURA CITADA}

ANDRADE, S. S. - Gênese c classificação de solos de três catenas nos Municípios de Piracicaba e Rio Claro. Dissertação apresentada à Escola Superior de Agricultura "Luiz de Queiroz", da Universidade de São Paulo para obtenção do título de Mestre. 74 pp. 1971.

BENNEMA, J.; JONGERIUS A. \& LEMOS, R. C. - Micromorphology of some oxic and argillic horizons in south Brazil in relation to weathering sequences. Geoderma 4: 333-355. 1970.

BREWER, R. - Fabric and Mineral Analysis of Soils. John Wiley and Sons, Inc., New York, XIII 470 pp. 1964.

BUOL, S. W. \& HOLE, F. D. - Clay skin genesis in Wisconsin soils. Soil Science Society of America Proceedings 25(5) : 377-379. 1961.

CARVALHO, A. - Study of Terra Roxa Estruturada and Latossolo Roxo on a topographic sequence in São Paulo State, Brazil. A thesis presented in partial fulfillment of the requirements for the degree of Master of Science (Soil Science) of the University of Newcastle upon Tyne. III $93 \mathrm{pp} .1970$.

COMISSÃO DE SOLOS DO CNEPA. - Levantamento de reconhecimento dos solos do Estado de São Paulo. Boletim n. ${ }^{\circ} 12$ do Serviço Nacional de Pesquisas Agronômicas, XI 634 pp. 1960.

DEMATTE, J. L. I. - Estudo pedológico de perfis da série Ibitiruna. Tese apresentada à Escola Superior de Agricultura "Luiz de Queiroz" da Universidade de São Paulo para obtenção do título de Doutor. 83 pp. 1968.

DEMATTE, J. L. I. - Gênese e classificação dos solos originados de sedimentos do grupo geológico Estrada Nova no Município de Piracicaba. Tese apresentada 
à Escola Superior de Agricultura "Luiz de Queiroz" da Universidade de São Paulo para obtenção do título de Livre-Docente. v 123 pp. 1970.

FREI, E. \& CLINE, M. G. - Profile studies of normal soils of INew York: II Micromorphological studies of the Gray-Brown Podzolic - Brown Podzolic soil sequence. Soil Science 68(4): 333-344. 1949.

McCALEB, S. B. - Profile studies of normal soils of New York: IV Mineralogical properties of the GrayrBrown Podzolic - Brown Podzolic soil sequence. Soil Science 77(4) : 319-333. 1954.

MONIZ, A. C. \& JACKSON, M. L. - Quantitative mineralogical analysis of brasilians soils derived from basic rocks and slate. Wisconsin Soil Science Report 212. 24 pp. 1967.

MOURA FILHO, W. - Characterization of the physical, chemical and micromorphological changes engendered by the cultivation of a soil in the Triangulo of Minas Gerais. Brazil. A thesis submitted to the Graduate Faculty of North Carolina State University at Raleigh in partial fulfillment of the requeriments for the degree of Master of Soil Science. vi $55 \mathrm{pp} .1968$.

MOURA FILHO, W. - Studies of a Latosol Roxo (Eutrustox) in Brazil. clay mineralogy, micromorphology effect of ion release, and phosphate reactions. A

thesis submitted to the Graduate Faculty of North Carolina State University at Raleigh in partial fulfillment of the requirements for the degree of Doctor of Philosophy. vIII $57 \mathrm{pp} .1970$.

NETTLETON, 'W. D.; FLACH, K. W. \& BRASHER, B. R. - Argillic horizons without clay skins. Soil Science Society of America Proceedings 33(1) : 121-125. 1969.

PETTAPIECE, W. W. \& ZWARICH, M. A. - Micropedological study of a chernozemic to Grey Wooded sequence of soils in Manitoba. The Journal of Soil Science 21(1) : 138-145. 1970.

RANZANI, G. - Pequeno guia para levantamento de solos. Escola Superior de Agricultura "Luiz de Queiroz", Universidade de São Paulo, Piracicaba. 2." edição, $22 \mathrm{pp} .1968$.

RANZANI, G.; FREIRE, O. \& KINJO, T. - Carta de Solos do Município dee Piracicaba. Escola Superior de Agricultura "Luiz de Queiroz", Piracicaba. 85 pp. 1966.

SIMONSON, R. 'W. - Outline of a generalized theory of soil genesis. Soil Science Society of America Proceedings 23(2): 152-156. 1959.

SMECK, N. E.; WILDING, L. P. \& HOLOWAYCHUK, N. - Genesis or argillic horizons in Celina Morley soils of western Ohio. Soil Science Society of America Proceedings 32(4) : 550-556. 1968.

SOIL SURVEY STAFF. - Supplement to Soil Classification System (Seventh Approximation). Second Printing. Soil Conservation Service, United States Department of Agriculture. 207 pp. 1967.

TEIXEIRA MENDES, A. C.; FALCI, S. C. \& DEMATTE, J. L. I. - Secções Delgadas de solos: método de impregnação Anais da Escola Superior de Agricultura "Luiz de Queiroz", 30: 35-48. 1973. 